\title{
Social Media Impact on Students Academic Performance Based on Sleeping Hours
}

\author{
A. Fedrick Akshay A, S. Sudha, S. Ajit
}

\begin{abstract}
Social media is an effective communication tool for the people to communicate with others all over the world, the evolution of social media emerges day to day mostly by the students than the working people. This research is constructed to find the effects of social media on the academic performance of the students based on their daily activities and sleeping hours. It is descriptive based research design. The sample of 160 students of 87 males and 73 females from various courses such as Engineering, Management, Arts and Science has been covered from different colleges in Chennai using non-probabilistic convenient sampling. The data is collected from the students by developing 23 questions in a questionnaire and distributed via both online and offline and analysed using Pearson's correlation of partial and bivariate on various variables on SPSS V23. The result shows there is a significant relationship between sleeping hours and Usage rate on social media. It also reveals that the sleeping hours has a direct effect on the variables such as Academic performance level, Interaction with teachers, Concentration level on class lectures and stressed, depressed, sleepiness rate of students.
\end{abstract}

Keywords: social media, students' academic performance, sleeping hours, concentration and interaction to lectures, social media addictions

\section{INTRODUCTION}

The evolution of internet from 1950's enables the user to share data all over the world. Where that time it was difficult to communicate with friends over telephone network, To make the people to be connected over internet the social media came to existence from 1997which emerges into a most important part of people lives day to day, the growth of smartphones and internet attracts most of the youngsters into social media such as Facebook, Instagram, WhatsApp, YouTube, Snapchat, and Twitter, etc. However, The initial motive of social media is to be a communication tool to be connected with friends through the internet but later on, it emerges into a platform for Networking, sharing of feelings, Entertainments, Knowledge gathering and so on. The increase in usage of social media makes the users spend most of their time in the daily routine that divides the world into online and offline. Students are the major users of social media over a long time as they have fewer commitments and work schedule in academic life compared to the people who work in an organization.

\section{STATEMENT OF PROBLEM}

The advancement of smartphones and internet leads the students into social media addiction by the psychological effects of dopamine generated by neurons on brain of the users,

Revised Manuscript Received on December 16, 2019.

A. Fedrick Akshay, Department of MBA, St. Joseph's College of Engineering, Chennai, India. Email: fedrickakshay@gmail.com

S. Sudha, Department of MBA, St. Joseph's College of Engineering, Chennai, India. Email: sudhadharshni@gmail.com

S, Ajit, Department of MBA, St. Joseph's College of Engineering, Chennai, India. Email: ajitsam@gmail.com
Where it not only consumes the productive hours of the students but also leads to improper sleeping habits by using it in the night time. The students should sleep minimum of 8 hrs at night to revive for the next day, which is not followed by most of the students nowadays. These non-sleeping habits indirectly affect the concentration level of the student towards lectures leading to a decrease in academic performance level.

\section{OBJECTIVE OF STUDY}

$>$ To find whether the overuse of social media has an effect on the academic performance level of students

$>$ To find the interaction level of students who overuse social media.

$>$ To determine that improper sleeping habits of the students due to social media has a direct impact concentration level on class lectures.

\section{HYPOTHESIS}

H01 Excessive use of social media negatively impacts sleeping hours.

H02 Interaction with teachers positively impacts academic performance controlled by sleeping hours.

H03 Stress, Depression, sleepiness negatively impacts on the concentration level of lectures controlled by sleeping hours.

\section{LITERATURE REVIEW}

The social media effects on the academic performance level of college student article by Gilbert M. Talaue1, Ali AlSaad, NaifAlRushaidan, Alwaleed AlHugail, Saad AlFahhad (2018), where they describe that social media may impact on both positive and negative way, It based on the students who use them with responsibility.

The social media grows as an efficient form of communication, It allows people to be connected with their friends, Interact socially among various groups, However, excessive use of social media may lead to an addiction that causes serious consequences on the academic progress of students said by the author Bernard John Kolan and Patience Emefa (2018).

The students who addicted to social media are lacking in time management, Low academic performance and also leads to malnourishment and illness explained by the authors Sandra Okyeadie Mensah and Dr. Ismail Nizam (2016).

The study conveys that social media is an effective tool that can be used for academic purpose by sharing notes, Interacting withteachers after classes and clarifying doubts, It says that students should be responsible to use these technologies in a good way by the authors Waleed Mujahid 
Al-Rahmi, MohdShahizan Othman (2016).

The students using social media resulted in low academic performance level said by the authors Agwi Uche Celestine \&Ogwueleka Francisca Nonyelum (2018), The author recommends students to use their time productively and to minimize the usage of social media.

\section{METHODOLOGY}

The research is adopted a descriptive research design and data is collected from 160 students of 87 males and 73 females from various courses such as Engineering, Management, Arts and Science has been covered from different institutions in Chennai based on non-probabilistic convenient sampling method. The questionnaire is developed consisting of 24 questions developed from the constructs of research by the author Saba Mehmood \&TarangTaswir from the literature, The Effects of Social Networking Sites on the Academic Performance of Students in College of Applied Sciences, Nizwa, Oman (2013) and distributed via both online and offline and analysed using Pearson's correlation of partial and bivariate on various variables on SPSS V23.

\section{DATA ANALYSIS AND FINDINGS}

In this analysis the demographic data are collected from the sample size of 160 students of male $54.40 \%$ and female $45.60 \%$ pursuing various courses such as Engineering, Management, Arts, MS. It is found that only 21.30 has more interaction to daily lectures and about $71.90 \%$ of students are affected by depression, stress, laziness, attention deficit disorder.

The data obtained from the survey conducted is analysed. The analysis is based on the hypothesis raised to guide the study.

H01 Excessive use of social media negatively impacts sleeping hour.

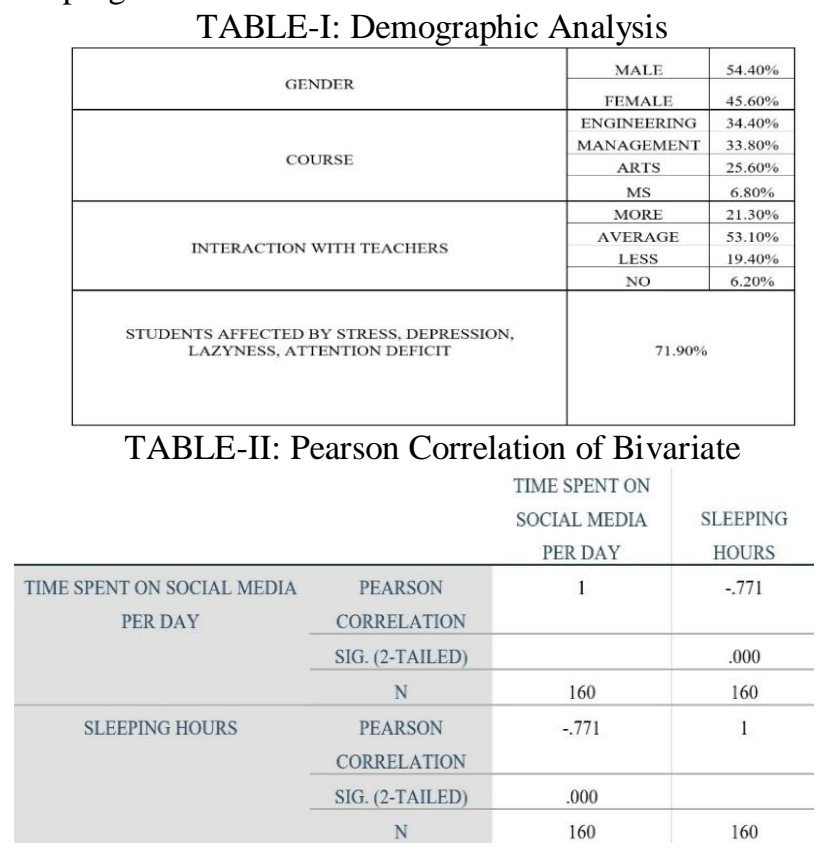

Table II shows the Pearson correlation of the bivariate test between time spent on social media per day and sleeping hours.

The significance value obtained is 0.000 with correlation value on sleeping hours -0.771 . The significance value is less than 0.05 at $5 \%$ level of significance. Therefore, the increase in usage time of social media reduces the sleeping hours of the students.

H02 Interaction with teachers positively impacts academic performance controlled by sleeping hours.

H03 Stress, Depression, sleepiness negatively impacts on the concentration level of lectures controlled by sleeping hours.

Table III shows the Pearson correlation of parity test between academic performance level, interaction with teachers, concentration level on lectures and stress, depressed, sleepiness in the academic period. The significance value obtained between academic performance level and interaction with teachers is 0.000 with a positive correlation value of teacher interaction level is 0.316 . Hence the significance value is less than 0.05 at $5 \%$ level of significance.

This shows an increase in interaction with teachers considerably increases the academic performance level controlled by sleeping hours.

\section{TABLE-III: Pearson Correlation of Partial}

\begin{tabular}{|c|c|c|c|c|c|c|}
\hline \multicolumn{3}{|c|}{ CONTROL VARIABLFS } & $\begin{array}{c}\text { ACADEMIC } \\
\text { PERFORMANCE } \\
\text { LEVEL }\end{array}$ & $\begin{array}{l}\text { NTERACT } \\
\text { WITH } \\
\text { TEACHERS }\end{array}$ & $\begin{array}{l}\text { CONCENTRATE } \\
\text { ONLECTURES }\end{array}$ & $\begin{array}{c}\text { STRESSED, } \\
\text { SLEEPY IN } \\
\text { ACADEMIC } \\
\text { PERIOD }\end{array}$ \\
\hline \multirow{12}{*}{ HOURS } & ACADEMIC & CORRELATION & 1.000 & .316 & .092 & -.034 \\
\hline & PERFORMANCE LEVEL & $\begin{array}{l}\text { SIGNIFICANCE } \\
\text { (2-TAIL.FD) }\end{array}$ & & .000 & .249 & .670 \\
\hline & & DF & 0 & 157 & 157 & 157 \\
\hline & INTERACT WIIH & CORRELATION & .316 & 1.000 & .121 & .108 \\
\hline & TEACHERS & $\begin{array}{l}\text { SIGNIFICANCE } \\
\text { (2-TAILED) }\end{array}$ & .000 & . & .130 & .177 \\
\hline & & DF & 157 & 0 & 157 & 157 \\
\hline & CONCENTRATE ON & CORRELATION & .092 & .121 & 1.000 & .286 \\
\hline & LECTURES & $\begin{array}{l}\text { SIGNIFICANCE } \\
\text { (2-TAIIFD) }\end{array}$ & .249 & .130 & . & .000 \\
\hline & & DF & 157 & 157 & 0 & 157 \\
\hline & STRESSED, DEPRESSED, & CORRELATION & -.034 & -.108 & -.286 & 1.000 \\
\hline & $\begin{array}{l}\text { SLEEPY IN ACADEMIC } \\
\text { PERIOD }\end{array}$ & $\begin{array}{l}\text { SIGNIFICANCE } \\
\text { (2-TAIIFD) }\end{array}$ & .670 & .177 & .000 & . \\
\hline & & $\mathrm{DF}$ & 157 & 157 & 157 & 0 \\
\hline
\end{tabular}




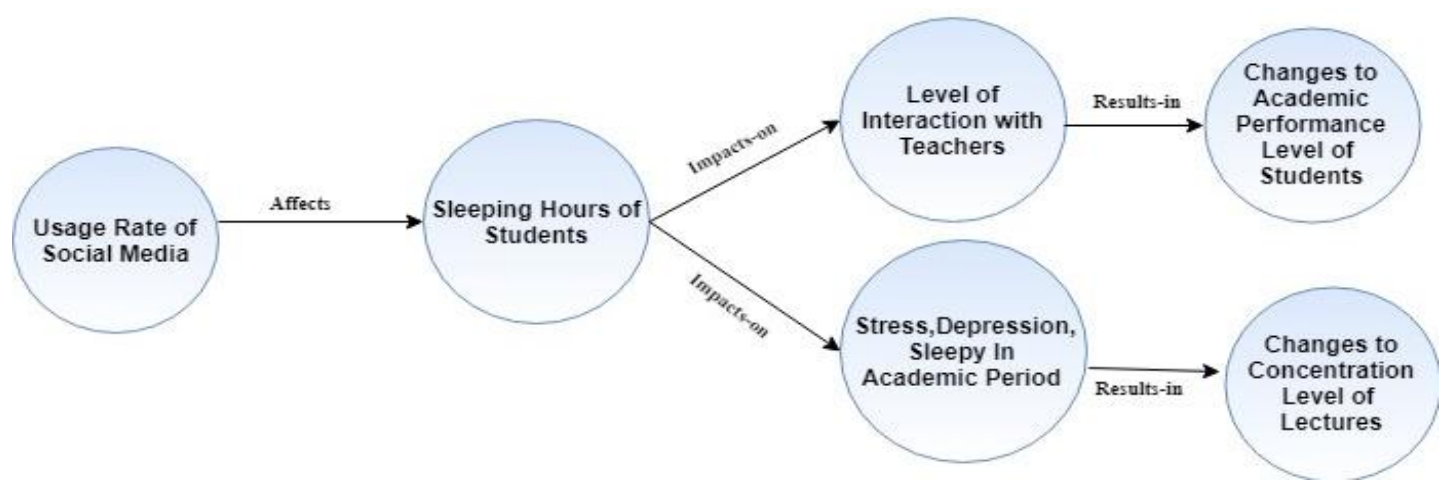

Fig.1 Graphical framework

The significance value obtained between concentration level on lectures and stressed, depressed, sleepiness rate in academic period is 0.000 with a negative correlation of concentration level of lectures is -0.286 . Hence the significance value is less than 0.05 at $5 \%$ level of significance. This shows an increase in stress, depression, sleepiness considerably reduces the concentration level of students.

The graphical database model represents that usage of social media affects the sleeping hours of students negatively which has a direct impact on interaction level and stress, depression, sleepiness rate of students that results in concentration level and academic performance of the students.

Proper sleeping habit is most important to the students because they have more mental work in their academic period than physical work, It is necessary for the students to sleep at least $8 \mathrm{hrs}$ a day so that they can start the next day with freshness which helps them to listen to the lectures more efficiently to grow their knowledge.

Figure 2 shows the social media usage cycle of users who affected by dopamine. The user use the social media repeatedly as per the cycle based on level of addiction. Where most of the students are attracted to social media now a days as it serves as a medium to keep them updated to recent trends, share their feelings to others and to show themselves as good in the society.

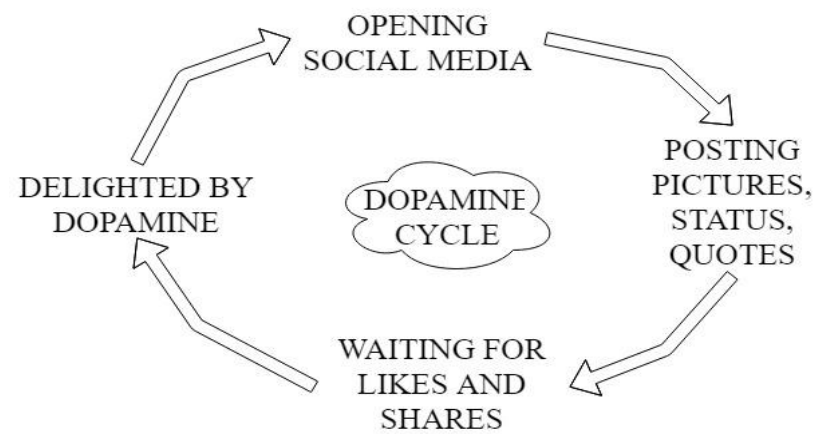

Fig.2 Dopamine Cycle of Social Media

Whenever a student posts some information in social media, if it has been liked or shared by other users, they feel delighted as their views are been accepted by the society, they feel themselves as superior which makes them to spendtime in social media for more hours than in direct interaction with the people.
This is due to the neurochemical transmitted from neurons in various part of the brain of users called Dopamine.

Where the users of social media want their own views to be followed by others. This is a psychologically effects that makes people to post more and more pictures, quotes, views, on social media to get more dopamine release from neurons which make them to feel delighted. But finally, these users ended with the reality of being lonely.

However the social media is good if it used as an communication tool, But the social media network drives the user psychologically addicted to social media.

\section{CONCLUSION}

Based on the findings, social media occupies the most important part of the student's life. It consumes most of their productive hours and results in anxiety, depression, loneliness, attention

deficit, hyperactivity disorder, and addiction. The students who addicted by dopamine spend excess time on social media sleeps only fewer hours in the night time. This makes them become stressed and sleepy in their daily classes which make in the reduction of the concentration level of students. This study also reveals that students who do not have proper sleeping habit tend to be less interactive to the lectures that result in poor academic performance.

\section{RECOMMENDATIONS}

The motive of social media is to be connected with friends online. Technology grows day today, we cannot simply blame these technological advancements as a barrier to the growth of students. The impact of social media in negative or positive is based on the way the user who uses them. The students should aware of these psychological effects and use the technologies with some limitations. These social media not only affect the academic performance of students but also serves as a tool to share notes and gather knowledge between students and teachers.

The students should realize what is more important in life and prioritize their daily activities accordingly. They should use social media in an effective way with certain limits and have the responsibility to spend their productive hours for achieving good grades in their academic performance. 


\section{REFERENCES}

1. Aditya Gaurav (2018). "The Serious Matter of SmartPhone Addiction". [Online] Available: https://theasiak.wordpress.com/2018/09/30/theserious matter-of-smartphone-addiction/

2. Farzana Parveen (2012), "Impact of Social Media Usage On Organizations",[Online] Available: http://www.pacisnet.org/file/2012/ PACIS2012-128.pdf

3. Henna Merenheimo (2018), "A Study About Student's Study Habit". [online]Available: https://www.theseus.fi/bitstream/handle/10024/152508 /thesis\%20merenheimo.pdf?sequence $=1$ \&isallowed=y

4. Kathleen Davis FNP (2019), "what's to know about sleep deprivation", [Online]Available:

https://www.medicalnewstoday.com/articles/307334.php

5. Mittuniversitetet (2017), "Sleeping Habits". [Online] Available: https://portal.miun.se/web/international-student/sleeping-habits

6. National sleep foundation (2016), "Teens and Sleep", [Online] Available: https://www.sleepfoundation.org/articles/teens-and-sleep

7. Radhika Kapur (2018), "Factors Influencing the Academic Performance in India".[Online] Available: https://www.researchgate.net/publication/324819

919_factors_influencing_the_students_academic_performance_in_seco ndary_schools_in_india

8. Robert Preidt (2017), "Poor Sleep Habits = Poor Grades". [Online] Available:

https://www.webmd.com/sleepdisorders/news/20170612/poorsleep habits-61-poor-grades

9. Santhosh Kumar D (2018), "How Dopamine Driven Feedback Loops Work?", [Online] Available: https://digitash.com/technology/internet/how-dopamine-drivenfeedback-loops-work/

10. SharunaSagaren (2018), "The Impact of Sleep on Academic Performance". [Online] Available: https://www.studyinternational.com/news/ the-impact-of-sleep-onacademic-performance/

11. Sophia (2019), "Social Media Addiction: Meaning, Symptoms, Causes, Effects,andTreatment".[Online] Available: http://www.thewisdompost.com/ essay/addiction/social-mediaaddiction/social-media-addiction-meaning-symptoms-causes effectstreatment/1293

\section{AUTHORS PROFILE}

A. Fedrick Akshay is a student from the Department of MBA, St. Joseph's College of Engineering, Chennai who graduated as Electronic and Communication engineer from the same college.

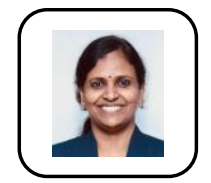

Dr. S Sudha is an Associate Professor from the Department of MBA, St. Joseph's College of Engineering, Chennai. She received her Doctorate from Madurai Kamaraj University, Madurai. She has several years of experience in the areas of teaching, research, student affairs and arranging / organized workshops and National level student symposium. She has several research publication in well known International Journal's and conferences and produced doctorates from various universities.

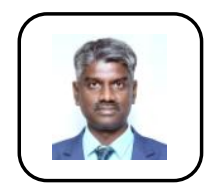

Dr. S Ajit is an Assistant Professor from the Department of MBA, St. Joseph's College of Engineering. He received his Doctorate in Management (Marketing) from Bharathiar University, Coimbatore. He has 15 years of experience in teaching and has published papers in reputed International Journals. 